\title{
A (IN)ESPERADA PANDEMIA E SUAS IMPLICAÇÕES PARA O MUNDO DO TRABALHO
}

\author{
LA PANDEMIA (NO)ESPERADA Y SUS IMPLICACIONES \\ PARA EL MUNDO DEL TRABAJO
THE (UN)EXPECTED PANDEMIC AND ITS IMPLICATIONS
FOR THE WORLD OF WORK

\author{
Kelen Christina Leite ${ }^{1}$
}

${ }^{1}$ Universidade Federal de São Carlos, Sorocaba/SP, Brasil.

\begin{abstract}
RESUMO: O novo coronavirus $S A R S-C o V$-2 é capaz de evidenciar os limites impostos pelas políticas neoliberais vigentes há mais de 40 anos, explicitando as profundas desigualdades e fragilidades das sociedades capitalistas. Os países mais atingidos pela pandemia enfrentam as consequências de anos de políticas de austeridade que comprometeram seus sistemas públicos de saúde e suas capacidades de resposta neste momento. O objetivo do artigo é relacionar as análises econômicas e políticas sobre o neoliberalismo com os estudos recentes sobre a erosão das democracias, a ascensão da extrema-direita e de governos autoritários no mundo, incluindo o Brasil, com ênfase na constituição das subjetividades diante do chamado neoconservadorismo, e, a partir desta relação, analisar a pandemia da Covid-19 e algumas de suas implicações para o mundo do trabalho. Quanto aos procedimentos metodológicos, este artigo é produto de pesquisa bibliográfica e reflexão crítica realizada sobre diferenças e desigualdades na contemporaneidade.
\end{abstract}

PALAVRAS-CHAVE: Covid-19; Trabalho; Neoliberalismo; Precariedade; Democracia.

RESUMEN: El nuevo Coronavirus $S A R S-C o V-2$ es capaz de mostrar los límites impuestos por las políticas neoliberales vigentes desde hace más de 40 años, explicando las profundas desigualdades y debilidades de las sociedades capitalistas. Los países más afectados por la pandemia enfrentan las consecuencias de años de políticas de austeridad que han socavado sus sistemas de salud pública y su capacidad de respuesta en este momento. El objetivo del artículo es relacionar los análisis económicos y políticos del neoliberalismo con estudios recientes sobre la erosión de las democracias, el auge de la extrema derecha y los gobiernos autoritarios en el mundo, incluido Brasil, con énfasis en la constitución de subjetividades frente al neoconservadurismo y, a partir de esta relación, analizar la pandemia de Covid-19 y algunas de sus implicaciones para el mundo del trabajo. En cuanto a los procedimientos metodológicos, este artículo es producto de la investigación bibliográfica y la reflexión crítica realizada sobre las diferencias y desigualdades contemporáneas. PALABRAS CLAVE: Covid-19; Trabajo; Neoliberalismo; Precariedad; Democracia.

ABSTRACT: The new SARS-CoV-2 coronavirus is capable of showing the limits imposed by neoliberal policies in force for over 40 years, explaining the profound inequalities and fragilities of capitalist societies. The countries hardest hit by the pandemic face the consequences of years of austerity policies that have compromised their public health systems and, therefore, their response capacities at this time. The objective of the article is to relate the economic and political analysis of neoliberalism with recent studies on the erosion of democracies, the rise of the extreme right and authoritarian governments in the world, including Brazil, with an emphasis on the constitution of subjectivities in the face of the so-called neoconservatism. The article also aims to analyse, from this relationship, the Covid-19 pandemic and some of its implications for the world of work. As for methodological procedures, this article is the product of bibliographic research and critical reflection carried out on contemporary differences and inequalities.

KEYWORDS: Covid-19; Work; Neoliberalism; Precariousness; Democracy. 


\section{Introdução}

Os coronavírus constituem-se em um grupo de vírus já presente entre humanos, conhecidos desde meados dos anos de 1960, causadores, em grande parte das vezes, de resfriados e gripes comuns. Em 2002 identificou-se, na China, a cepa SARS-Cov (Síndrome Respiratória Aguda Grave - ou SRAG) causada, portanto, por um coronavírus que, embora se assemelhando a outras doenças respiratórias, apresentou quadros mais graves da doença, com cerca de 800 mortes notificadas no mundo, não tendo sido mais rastreada desde 2004. Em 2012 outra variante de coronavírus foi identificado na Arábia Saudita, a Mers-Cov (Síndrome Respiratória do Médio Oriente). Embora a Mers seja uma doença grave, levando a morte cerca de $36 \%$ de quem adoece, é menos contagiosa que a $S A R S$-Cov, que pode ser fatal em até $10 \%$ dos casos. Já no caso da Covid-19, doença causada pela SARS-Cov-2, constata-se, até o momento, que cerca de $80 \%$ dos casos confirmados apresentam sintomas leves ou são assintomáticos, 15\% são infecções graves, necessitando de oxigênio, e 5\% muito graves, necessitando de ventilação assistida por meio de respiradores. (Tesini, 2020).

O coronavírus $S A R S-C o V-2$ foi identificado pela primeira vez em seres humanos na cidade de Wuhan, China, em dezembro de 2019 e transformou-se em uma pandemia, atingindo, em 22 de julho de 2020, 15.214 .970 casos confirmados e 617.433 mortes no mundo todo. O Brasil, segundo o Ministério da Saúde (2020), apresentava 2.167.988 casos confirmados e 81.628 mortes.

Surtos, epidemias e pandemias a partir de novos vírus não são eventos inesperados, pelo contrário, são eventos esperados por muitos cientistas. Para os estudiosos e pesquisadores do influenza a questão não é se um surto, uma epidemia ou uma pandemia irão ocorrer em algum momento, mas sim quando e quão letal serão. Outro elemento preocupante é se os sistemas de saúde dos vários países estarão preparados para enfrentar uma emergência deste tipo. Segundo Dennis Carrol (Berger, 2020), pesquisador do influenza, o ponto decisivo é com qual frequência o mundo enfrentará essas situações, uma vez que, com o crescimento populacional e a invasão humana em áreas habitadas por vírus, sobretudo por meio do desmatamento, fará com que esses vírus saltem para os humanos com cada vez mais frequência. Portanto, um vírus com capacidade de difusão global já era esperado pelos cientistas e pela própria Organização Mundial da Saúde (OMS) e, tendo emergido, foi capaz de externar muitos dos limites impostos à sociedade pelo modo de produção capitalista com suas políticas neoliberais vigentes há mais de 40 anos.

A pandemia de $S A R S-C o v-2$ possui a capacidade de explicitar, visibilizar e elucidar as profundas desigualdades e fragilidades das sociedades capitalistas, ou seja, ela é capaz de exacerbar a capacidade destrutiva e insustentável do modo de produção capitalista e suas profundas desigualdades, fundadas em classe, gênero, raça/etnia, sexualidade, geração e demais marcadores sociais da diferença.

Assim, o objetivo deste artigo é realizar uma discussão das implicações e possíveis consequências da Covid-19 para o mundo do trabalho, com ênfase no caso brasileiro, diante de relações trabalhistas já precárias e precarizadas pelas políticas neoliberais de austeridade que produzem não apenas efeitos econômicos e políticos, mas também outras e novas subjetividades no contexto de questionamento e/ou erosão das democracias liberais. A discussão será realizada, sobretudo, a partir do estabelecimento de um diálogo com as obras de autores como Dardot e Laval (2016) e Wendy Brown (2019). 
Quanto aos procedimentos metodológicos, este artigo é produto de pesquisa bibliográfica a partir de uma perspectiva marxiana e neomarxista em diálogo com uma revisão crítica da bibliografia. Tal debate centra-se nas questões relativas ao neoliberalismo, a crise da democracia e ao mundo do trabalho, tendo por base recortes mais recentes. Reflexão crítica esta que também se pauta pelo trabalho realizado junto aos pesquisadores do Programa de Pós-graduação em Estudos da Condição Humana da Universidade Federal de São Carlos (UFSCar), que vêm se debruçando sobre as temáticas das desigualdades e diferenças por meio de questões relacionadas à classe, gênero, raça/etnia, sexualidade e outros marcadores, ampliando, com isso, a capacidade de análise de temas complexos e interdisciplinares como a pandemia de $S A R S$-Cov-2 e suas implicações.

Para a consecução do objetivo proposto, primeiramente, será apresentada uma breve discussão acerca de alguns elementos do neoliberalismo que estruturam a política econômica, bem como capturam a subjetividade e constroem novas racionalidades que terão consequências para o mundo do trabalho. Será realizada, ainda, uma discussão acerca de como mudanças no interior do neoliberalismo produziram e estão produzindo um questionamento das democracias liberais que, paulatinamente, vão transformando o mundo do trabalho. A seguir serão discutidos os elementos que enquadram esta pandemia e, provavelmente, outras que virão, a partir da perspectiva do mundo do trabalho.

\section{Alguns Apontamentos sobre o Neoliberalismo}

O novo coronavírus mostrou toda sua violência já em seu início, e o mundo olhou assustado para a China e sua política de contenção e de isolamento da população. Para muitos ocidentais, tais políticas de contenção pareciam exageradas e típicas de países que exercem forte controle sobre suas populações, algo impensável no ocidente "livre" e "democrático".

Com a chegada do vírus ao continente europeu, atingindo fortemente o norte da Itália, região próspera e rica daquele país, o vírus foi logo identificado, por alguns, como não classista, ou seja, o antigo mito de que doenças infecciosas não possuem barreiras sociais veio à baila. No entanto, embora o vírus tenha capacidade de atingir indistintamente a população, ele não produz as mesmas consequências quando atinge sociedades mais desiguais e, também, mais racistas, como Estados Unidos e Brasil, países nos quais, dados preliminares, apontam um avanço maior de mortes entre a população pobre e negra. Nos EUA, estima-se que haveria três mortes de negros(as) para cada branco(a). Existe, ainda, muitas dificuldades para produzir dados acurados devido a fatores, como imprecisão no preenchimento dos dados ou a ausência de declaração de raça/etnia. Outra questão importante, nos EUA, relaciona-se com a ausência de um sistema público de saúde e a desigualdade de renda entre a população branca e negra (Wiston-Salem, 2020). No Brasil, segundo nota técnica de pesquisadores do NOIS (Núcleo de Operações e Inteligência em Saúde) da PUC (Pontifícia Universidade Católica) do Rio de Janeiro, mais da metade, 54,8\%, dos(as) negros(as) que se internaram em hospitais no Brasil para tratar a Covid-19 morreram, enquanto nos(as) brancos(as) essa letalidade é de 37.9\%. Explicitando todas as desigualdades geradas pelo racismo estrutural da sociedade brasileira (Batista et al., 2020).

Nos EUA, a ausência de um sistema público universal de saúde, em que leitos vazios em hospitais, estoques de equipamentos, ventiladores, máscaras etc. representam prejuízo, torna o país mais vulnerável diante de situações pandêmicas. Já países com sistemas 
públicos de saúde encontraram grandes dificuldades no enfrentamento da pandemia por outros motivos, dentre os quais, o mais relevante advém das políticas de austeridade impostas por décadas de neoliberalismo, tendo de enfrentar, ainda, a falta de insumos de produtos sanitários disponíveis no mercado, causada pela concentração da produção em determinados lugares.

Compreender as implicações da atual crise sanitária global se faz sempre mais necessária, e requer também a compreensão do neoliberalismo e como este se constitui enquanto política econômica e, para tanto, são vários os autores que fizeram e fazem essa discussão (Anderson, 1995; Antunes, 2000; Braga, 2017). Importante também é o debate sobre outro aspecto do neoliberalismo relacionado à captura das subjetividades (Alves, 2011 ). Outra relevante reflexão na compreensão das implicações do neoliberalismo é dada por Dardot e Laval (2016), que apresentam a ideia, segundo a qual, o neoliberalismo enseja a constituição de uma nova racionalidade que constitui-se como uma nova razão do mundo. Essa nova racionalidade atinge não apenas os indivíduos, mas também grupos, associações, movimentos sociais e partidos políticos.

No entanto, a perspectiva sobre o neoliberalismo aqui adotada - que traz novos elementos para o debate - se aproxima de Brown (2019), ao ressaltar que, para além de todas as características mencionadas anteriormente, é necessário entender o fenômeno do neoliberalismo também por meio de uma abordagem que consiga contemplar a questão da moral, negligenciada nas análises anteriores, pois é essa questão que, em aparência antitética aos ideias liberais, ajuda a compreender o ataque à democracia, aprofundando sua erosão e o processo de (des)democratização pelo qual passam muitas sociedades.

No espaço deste artigo, portanto, não se discutirá a gênese, o desenvolvimento e a implementação do neoliberalismo, tal discussão pode ser encontrada em vários autores, dentre os quais Anderson (1995), Leite (2007, 2020), Antunes (2000), Chesnais (2005), Braga (2017), Alves (2011), Dardot e Laval (2016). No entanto, cabe destacar que para o adequado enquadramento do neoliberalismo faz-se necessário ter presente que ele faz parte de um complexo processo de reestrutuação capitalista da sociedade, que produz continuamente uma precarização do trabalho e da vida que possui como ponto de inflexão a crise dos anos de 1970, configurando-se como uma crise do modo de regulação fordista/ keynesianista que, depois de atingir seu ápice, apresenta seus próprios limites e contradições internas abrindo um amplo processo de contra-reformas, dentre as quais a neoliberal, que avança até a crise de 2008, marco temporal para este artigo.

Assim, o acúmulo de tensões e de problemas não resolvidos no interior do capitalismo como os que desencadearam a crise de 2008; a tendência de aumento da desigualdade, não apenas em países emergentes, mas também nos países centrais; o aumento da pobreza; os desequilíbrios especulativos; a destruição da natureza; a crise urbana (habitação, saneamento, transporte, habitação); a exacerbação do racismo, da opressão de gênero, da xenofobia, do sexismo e o culto à ignorância e o desprezo à ciência prospectam dias cada vez mais difíceis com decisões políticas sempre mais críticas.

Todas essas questões se expressam, mais fortemente, diante da Covid-19, trazendo para o centro das discussões políticas e econômicas a necessidade de uma discussão mais profunda acerca dos serviços públicos, dos bens públicos, dos sistemas de proteção social e trabalhista, bem como a necessidade de se (re)discutir o papel do Estado na promoção e na garantida de direitos básicos ligados não apenas ao bem-estar da população, mas à própria vida. 
Tanto os países da União Europeia e os EUA, para permanecer apenas nesses dois pólos da dinâmica econômica, ao encontrarem-se diante dos desafios postos pela pandemia, fizeram - e continuam fazendo, como demonstram os jornais do mundo todo - o debate sobre a necessidade urgente de intervenção estatal. Adotaram medidas de intervenção do Estado na economia que reúne, neste momento, a concordância de expoentes de distintas matizes político-ideológicas, bem como de economistas de vertentes teóricas distintas (liberais, keyneisanos, neokeynesianos). O Estado é visto como agente capaz de frear a crise com medidas emergenciais; salvaguardar a vida, com políticas coordenadas no âmbito sanitário e de saúde e; induzir e sustentar a retomada do crescimento econômico no pós-pandemia.

No Brasil, por outro verso, conforme discutido por Dweck (2020), a política neoliberal do atual governo de Jair Bolsonaro, levada a cabo pelo ministro da economia Paulo Guedes, contribuiu para fragilizar as instituições e os instrumentos de política econômica imprescindíveis no combate à crise sanitária.

Constata-se que, mesmo diante da pandemia da Covid-19, não houve mudança no discurso neoliberal de Paulo Guedes, nem tão pouco de sua prática, ainda que sinais e alertas nacionais e internacionais tenham sido emitidos - no sentido que se deve abandonar, ainda que temporariamente, as amarras da relação dívida/PIB, do equilíbrio fiscal, do gasto e investimento público. Ainda assim, Guedes, em reunião ministerial de 22/04/2020, reforçou sua perspectiva ao dizer que: "Nós vamos ganhar dinheiro usando recursos públicos pra salvar grandes companhias. Agora, nós vamos perder dinheiro salvando empresas pequenininhas" (Mazeiro, 2020), ou seja, micro, pequenas e médias empresas, responsáveis por grande parte dos postos de trabalho e, portanto, da massa salarial do país, não deveriam ter políticas específicas dirigidas à elas. Nas diversas conferências online promovidas por instituições financeiras, o ministro reforçou a mensagem que a agenda de reformas estruturais não foram deixadas para trás e deverão ser retomadas. Deste modo, observou-se, ao longo dos últimos anos, no Brasil e no mundo, o avanço da implementação de políticas que degradaram os direitos trabalhistas por meio da redução dos custos salariais, da flexibilização de normas e leis protetoras do trabalho, ao mesmo tempo que expandiram a adoção de mecanismos não apenas de proteção ao mercado, mas de ampliação da esfera de seu domínio, adentrando e mercantilizando áreas como educação, saúde, cuidado, previdência, cultura, água, saneamento básico etc.

\section{Neoliberalismo e a erosão da democracia liberal}

Vive-se um difícil e delicado momento de enfraquecimento, de questionamento e de erosão das democracias liberais, fenômeno que, para além dos limites da própria democracia liberal, é também impulsionado pelo uso das novas tecnologias da informação que colaboraram com o advento, com a eleição e com a permanência de governos autoritários e hiper autoritários, colocando as sociedades ocidentais contemporâneas diante daquilo que Brown (2019) denomina (des)democratização ou pós-democracia. Isso se dá com intensidade ainda maior a partir da crise de 2008.

Assim, do mesmo modo que no curso da crise de 2008, alguns intelectuais e políticos prenunciaram o fim do neoliberalismo, hoje, outros tantos, dentre eles Pedro Rossi (2020), apontam que a atual crise sanitária poderia representar um questionamento profundo ao paradigma neoliberal ao mostrar que se o Estado pode, por meio da solidariedade social 
e esforço coletivo, mobilizar recursos para vencer o vírus, pode também vencer mazelas sociais como a miséria, a falta de moradia, o desemprego, os desafios ambientais, etc. O desafio global dos tempos atuais demandaria empenho e solidariedade comum. Do mesmo modo que no pós-segunda guerra houve uma profunda transformação das sociedades ocidentais, com a ascensão do modo de regulação fordista/keynesianista, a crise do coronavírus poderia marcar uma inflexão na história, estabelecendo novos padrões democráticos de relação entre Estado, mercado e sociedade.

O que observou-se, porém, no pós-crise de 2008, não foi o fim do neoliberalismo, como muitas análises prenunciavam, mas, pelo contrário, assistiu-se um certo renascimento, sob nova face, do neoliberalismo. Um neoliberalismo que passou a se mover de modo diverso em relação a como havia se movido até então, mostrando-se muito mais livre em suas ações de combate aos direitos sociais estabelecidos e muito mais potente.

A extrema-direita, juntamente com uma direita autoritária, ganhou força e expressão na última década utilizando-se de uma aprofundamento do discurso neoliberal transmutado. Em alguns países ela se fortaleceu e em outros ela surgiu expressivamente.

Os casos são vários: Recep Erdogan (Turquia) e Vladmir Putin (Rússia) conseguem a manutenção do/no poder por meio de várias manobras e mudanças nas legislações eleitorais, além do cerceamento da liberdade de expressão e de imprensa, dentre outras medidas. Viktor Orbán (Hungria) caminha pelo mesmo sentido e aprofunda medidas autoritárias, promovendo uma reforma constitucional conservadora centrada na família, na tradição, na ética e na religião, propagando sua defesa de uma democracia liberal. Crescimento significativo da extrema direita na Polônia com o partido nacionalista (Direito e Justiça) de Jaroslaw Kaczynski; a forte representação adquirida pelo partido Alternativa para Alemanha (AFD), partido nacionalista que, nas últimas eleições, conquistou vagas no parlamento; ascensão da extrema direita na Itália, tendo o partido Lega de Matteo Salvini apresentado-se como o primeiro partido do país em intenções de votos para as próximas eleições. E ainda, Narendra Modi (Índia) e Rodrigo Duterte (Filipinas). A situação do Reino Unido com o Brexit e a ascensão de Boris Johnson e, evidentemente, o Brasil, que em sua última eleição presidencial de 2018 elegeu Bolsonaro.

O sinal de alerta, porém, parece ter sido disparado com a eleição de Donald Trump em 2016, um presidente estadunidense que, pela primeira vez na história daquele país, despreza abertamente normas constitucionais básicas ao ameaçar não aceitar os resultados eleitorais, ao defender a prisão de sua concorrente, ao privilegiar estar ao lado de aliados mais autoritários do que estar próximo aos próprios membros do Partido Republicano (Mounk, 2018) e, embora outros governos com tais características já estivessem estabelecidos, é a partir da eleição de Trump, pela força política e econômica dos EUA, que inicia-se um grande debate sobre o futuro de uma democracia ameaçada, enfraquecida e restritiva quanto aos direitos e liberdades em nome da retomada do crescimento (medidas de austeridade) e da segurança nacional.

Todas essas realidades possuem alguns elementos em comum, pois conseguiram mobilizar, de acordo com o contexto de cada país, alguns sentimentos compartilhados que vão desde a desilusão com a política, com as instituições, com a falta de perspectivas, até a mobilização do racismo, da xenofobia, da LGBTfobia, da islamofobia, do sexismo, da misoginia, do nacionalismo, do patriotismo, do discurso anti-corrupção, dos valores cristãos; dos sentimentos anti-globalização, traduzidos no que denominam de anti-globalismo e, ainda, um forte sentimento anti-migração. 
Para Brown (2019), o momento se apresenta como um processo de difícil caracterização uma vez que soa pouco familiar algumas das associações presentes, hoje, nesses grupos, como: libertarianismo, moralismo, autoritarismo, nacionalismo, ódio ao Estado, conservadorismo cristão e racismo. Parece haver a junção de elementos clássicos do liberalismo - favorecimento do capital, esvaziamento do Estado, demonização do Estado e da coisa pública, ataque a políticas sociais de equidade, e exaltação da liberdade individual e, por outro lado, elementos que parecem seus opostos: nacionalismo, moralidade tradicional, antielitismo popular, demanda por políticas estatais de proteção social e econômica.

São grupos estes que

endossam a autoridade enquanto exibem desinibição social e agressão pública sem precedentes. Batem-se contra o relativismo, mas também contra a ciência e a razão, e rejeitam afirmações baseada em fatos, argumentação racional, credibilidade e responsabilidade. Desdenham dos políticos e da política enquanto manifestam uma feroz vontade de potência e ambição política... As agendas políticas liberais, as agendas econômicas neoliberais e as agendas culturais cosmopolitas geraram uma crescente experiência de abandono, traição e finalmente raiva por parte dos novos despossuídos, da população da classe trabalhadora e da classe média brancas do Primeiro Mundo e do Segundo. (Brown, 2019, pp. 10-11)

A compreensão política do neoliberalismo pressupõe, assim, a compreensão da natureza do projeto social e político que ele representou e promoveu desde os anos de 1930 e que passou a efetivar-se com a crise dos anos de 1970, transmutando-se a partir da crise de 2008 e trazendo, para seu interior, novos elementos. Os anos de 1990, por exemplo, foram caracterizados por um intenso processo de desregulamentação, flexibilização de normas e regras financeiras, desindustrialização de muitos países com a deslocalização de empresas que foram em busca de maiores e melhores condições de exploração da força de trabalho, instalando-se em países da Ásia, Leste Europeu e América Latina.

Chesnais já atribuía, anos atrás, ao processo de deslocalização em direção aos países que oferecem baixos salários, várias implicações:

A deslocalização de unidades produtivas decorre de relações, cuja iniciativa pertence aos grupos industriais e comerciais dos países que participam do oligopólio mundial e cujo efeito consiste em poder jogar em concorrência a oferta da força de trabalho de um lado para o outro. A expansão do sistema capitalista baseou-se na integração simultânea, no âmbito de Estados-nações "regulados", de três mercados: o mercado de mercadorias, o de capitais (e tecnologias) e o do trabalho. Pelo seu movimento de mundialização, o capital explode esta integração e, evidentemente, não se preocupa em reconstituí-la. O sistema mundial é fortemente integrado no aspecto financeiro e ainda mais quanto aos investimentos diretos. Mas não é integrado quanto ao preço de venda e às condições de utilização da força de trabalho pelas firmas. Estas têm toda liberdade para explorar como quiserem as diferenças na remuneração do trabalho, entre diferentes países e regiões. (Chesnais, 2005, p. 18)

Esse processo, apontado por Chesnais, evidencia dois pontos cruciais para o enfrentamento da pandemia: os problemas relativos à falta de insumos sanitários básicos e a questão relativa ao trabalho. 
A falta de integração/regulação do mercado de trabalho mundial demonstra suas consequências, sobretudo, pós-crise de 2008, provocando uma nova onda de ataques aos direitos trabalhistas, fragilizando os trabalhadores durante a pandemia.

Como evidenciado pela Organização Internacional do Trabalho (OIT) em 111 países, entre os anos de 2008 e 2014, ocorreram reformas nas regulamentações em relação ao trabalho. O relatório da OIT (2015) demonstra que o número de reformas aumentou desde o início da crise de 2008 e que a maioria das reformas foi aprovada em economias desenvolvidas e em desenvolvimento, sendo que $56 \%$ delas foram no sentido de diminuição dos níveis de regulamentação existentes. No curto prazo, o relatório aponta que os países que relaxaram suas regras, bem como níveis então existentes de proteção dos(as) trabalhadores(as), experimentaram um aumento na taxa de desemprego e não o contrário, ou seja, menos direitos não significa mais empregos.

Já nos países em desenvolvimento, o relatório da OIT aponta que o efeito não foi tão significativo, uma vez que esses países viram praticamente mantidos os seus níveis de emprego. Há que se ponderar, no entanto, que isso se deve ao fato de ter havido um deslocamento dos trabalhos de setores formais (por meio das demissões) para os setores informais. Deste modo, em ambos os grupos de economias, a desregulamentação está associada a uma queda na taxa de emprego nos anos subsequentes e não o contrário.

Assim, o processo de enfraquecimento das regulamentações do trabalho ocorridas entre 2008/2014 relaciona-se com a crise de 2008 e o aprofundar-se do neoliberalismo em sua nova fase e, evidentemente, com as consequências do processo de deslocalização das empresas, intensificado a partir dos anos de 1990, que beneficiou um processo de busca por mão-de-obra mais barata em países com fraca regulamentação do trabalho e movimento sindical forte e atuante. Portanto, essa situação, que desindustrializou vastas regiões, associada à crise de 2008 , ensejou as reformas feitas em países de maior regulamentação e maiores salários, pois há uma demanda, por parte do capital, de achatamento dos custos do trabalho. O crescimento do setor terciário, com salários mais baixos, também contribui para exercer pressão em direção a uma redefinição dos marcos regulatórios em relação ao trabalho e, por extensão, em muitos países, também em relação à Previdência.

O processo de deslocalização das empresas em busca de melhores condições de exploração da mão-de-obra e, portanto, a transferência da produção de produtos com baixo valor agregado para outros lugares, especialmente a Ásia, é um dos fatores da dificuldade que, hoje, o mundo encontra para suprir a rede de assistência à saúde de insumos básicos não mais fabricados nos próprios países, como máscaras, aventais, respiradores etc.

Outras características importantes do momento subsequente à crise de 2008 foram: a forte queda nos preços das commodities, afetando sobremaneira o Brasil; o fraco crescimento das economias nacionais; a crise da zona do euro, cujo exemplo maior foi a Grécia, mas também Espanha e Portugal e, por fim; o endividamento público, causado pela intervenção do Estado, em 2008, para garantir a sobrevivência de empresas e bancos, dando liquidez ao mercado, que passa a ser o foco das medidas econômicas e, portanto, de decisões de contenção de gastos e investimentos.

O resultado, portanto, das políticas de austeridade recaíram sobre os(as) trabalhadores(as) na forma de reformas trabalhistas e previdenciárias, na elevação das taxas de desemprego, no subemprego, na informalidade, na precarização, no aumento das desigualdades, da pobreza, da polarização social e política diante dos ajustes que excluem 
cidadãos do acesso a serviços e direitos. As respostas autoritárias, vinda das urnas, não faltaram a partir desse período.

Percebe-se, assim, que nesse processo, o neoliberalismo, bem como o capitalismo, mostra-se dotado de grande plasticidade, de grande capacidade de metamorfosear-se não apenas para se manter, mas também para aprofundar o seu domínio. A racionalidade neoliberal, que tudo mercantiliza e individualiza, da qual falam Dardot e Laval (2016), teria sido a base para a mobilização e a legitimação das forças antidemocráticas da segunda década do século XXI.

Por sua vez, Brown (2019, p. 17) ressalta que

nada fica intocado pela forma neoliberal de razão e de valorização, e que o ataque do neoliberalismo à democracia tem, em todo o lugar, infletido lei, cultura política e subjetividade política. Compreender as raízes e as forças da situação atual requer avaliar a cultura política e a reprodução subjetiva neoliberais, e não somente as condições econômicas e os racismos persistentes que geraram. Significa avaliar que a ascensão das formações políticas nacionalistas autoritárias brancas se deve à raiva instrumentalizada dos indivíduos abandonados economicamente e ressentidos racialmente.

O neoliberalismo é, portanto, e sempre mais, um sistema que busca desativar o jogo democrático e até mesmo desativar a própria política como atividade, ao buscar continuamente desacreditá-la. O regime neoliberal está impulsionando as sociedades para uma era pós-democrática, a democracia liberal, com todos os seus defeitos e seus limites, e está mudando profundamente por meio dos constantes ataques à sociedade e à prática da vida política (Brown, 2019).

Está-se diante, para dizer com Dardot e Laval (2016), de uma racionalidade política mundial que consiste em impor à sociedade, por meio dos governos, a mesma forma, a mesma norma, a mesma regra que guia a lógica do capital. Estaríamos e seríamos capturados, dominados por um modo de viver que impõe a competição como princípio de vida e a empresa como modelo para todas as instituições. Há, portanto,

uma espécie de retorno do recalcado na razão neoliberal - uma erupção feroz das forças sociais e políticas a que os neoliberais de uma só vez se opuseram, subestimaram e deformaram com seu projeto desdemocratizador. Isso significa que o neoliberalismo realmente existente apresenta [...] uma forma "enfurecida" de governo da maioria frequentemente denominada "populismo". (Brown, 2019, p. 26)

Assim, o neoliberalismo, seja pelas suas capacidades seja pela ineficiência da sua oposição, se reforça da hostilidade que ele mesmo gerou. O neoliberalismo é capaz - e está demonstrando - de desfrutar da raiva, das frustrações, dos ressentimentos provocados pelo próprio neoliberalismo, isto é, provocados pelas suas consequências socioeconômicas reforçando, com isso, o seu poder e a sua liberdade de ação. Esta liberdade de ação passa a minar as estruturas das democracias liberais, fazendo com que certos princípios e regras democráticas pareçam um obstáculo à política neoliberal. Portanto, a liberdade de imprensa, a liberdade de pensamento, a liberdade de crítica e a existência de outros modos de vida aparecem como obstáculos que devem ser superados e banidos. 
O jogo democrático propôs, até agora, uma política baseada em direitos, e estes, no entanto, são considerados não mais úteis, fazendo com que muitos acreditem que deles podem prescindir. Este é exatamente o motivo pelo qual também é necessário enfraquecer a pluralidade de ideias, de pensamento, de imprensa, enfraquecendo, quando e onde possível, o papel dos parlamentos, reforçando o poder do executivo ou, em alguns casos, reforçando o poder da magistratura.

Esta é uma tendência não apenas fruto das mudanças advindas de 2008, mas alguns elementos remontam às políticas pós-atentados de 11/09/2001, nos Estados Unidos, que inauguraram uma flagrante violação dos direitos individuais em nome da segurança nacional. Hoje, com a pandemia do novo coronavírus, novas violações, capturas de dados e controle da população estão sendo postos em prática, sem que haja percepção e análise adequada deste fenômeno.

Assim, parece estar em curso uma contra-revolução, sem revolução ("façamos a revolução antes que o povo a faça”) dirigida a uma parcela da população considerada perigosa mesmo não o sendo. Instaura-se uma guerra contra o inimigo interno (a esquerda, as feministas, os LGBTs, os comunistas, os imigrantes, os professores, a imprensa, as universidades, e a lista não tem fim), que muda segundo os países, mas que de qualquer modo possui sempre a mesma estratégia que completa a guerra econômica contra o inimigo externo, ou seja, a lógica do inimigo, mesmo que amplamente conhecida e perigosa, continua a impor-se diante do medo.

Para Brown (2019), esse momento de crise, marcado por um processo crescente de (des)democratização ou pós-democracia, é caracterizado pelo esvaziamento da política por parte do poder econômico e pelo imperativo de uma ordem concorrencial e competitiva, que adentra a vida social, permeando todas as relações sociais.

\section{Pandemia e mundo do trabalho}

A pandemia de Covid-19 move-se, portanto, neste cenário e, com o seu avançar, medidas necessárias de isolamento social e, em casos mais extremos, do confinamento total (lockdown), possuem repercussões imediatas sobre o mundo do trabalho, afetando trabalhadores(as), empresas, de modo particular as micro e pequenas empresas que, no caso brasileiro, correspondem a $99 \%$ dos estabelecimentos e $52 \%$ dos empregos com carteira assinada no setor privado (SEBRAE, 2020).

No mundo todo e, particularmente no Brasil, o impacto da Covid-19 não é o mesmo para todos(as) trabalhadores(as), refletindo e reforçando as desigualdades e desequilíbrios já existentes no interior do mercado de trabalho entre um núcleo de trabalhadores mais estáveis - com seus empregos mais regulamentados - e uma vasta massa de trabalhadores que viram, ao longo dos anos, mudanças que consentiram em: maior flexibilidade funcional, numérica e salarial; formas mais arbitrárias de contratação da mão de obra em relação aos prazos, horários de trabalho e salários; amplo processo de terceirização, subcontratação, trabalho por metas e/ou projetos com expressivo enxugamento do quadro de funcionário das empresas; uso cada vez mais intenso do trabalho intermitente - hoje plenamente (des)regulado no Brasil - intensificação da chamada 'pejotização'; do trabalho part-time (Leite, 2020). 
Essas são apenas algumas dentre tantas outras medidas que conduzem os(as) trabalhadores(as) para formas cada vez mais precárias de inserção no mercado de trabalho. Necessário enfatizar, ainda, a disseminação do chamado trabalho "uberizado", ou seja, o trabalho daqueles(as) trabalhadores(as) que não têm seus trabalhos reconhecidos, pois para os aplicativos esses são apenas usuários de uma plataforma digital.

O que a pandemia da Covid-19 faz é ressaltar, destacar, evidenciar essas condições relacionadas, sobretudo, aos(às) trabalhadores(as) informais, já precarizados(as), e também algumas categorias de autônomos(as).

Pode-se afirmar que a Covid-19 exibe todas as características de uma pandemia que explicita as desigualdades e diferenças de classe, gênero, sexualidade, raça/etnia. Embora os esforços de mitigação estejam convenientemente ocultos na retórica de que todos estamos juntos nesta guerra

as forças de trabalho, em muitas partes do mundo, são socializadas há muito tempo para se comportarem como bons sujeitos neoliberais, o que significa culpar a si mesmas ou a Deus se algo der errado, mas nunca ousar sugerir que o capitalismo pode ser o problema. Mas mesmo bons indivíduos que defendem o neoliberalismo podem ver que há algo errado com a maneira como esta pandemia está sendo respondida. (Harvey, 2020, online)

Alguns dados permitem demonstrar a magnitude dos problemas a serem enfrentados. Santos (2020) aponta, por exemplo, para o fato que medidas de isolamento social colocaram em quarentena, na Índia, 1,3 bilhão de habitantes. Considerando que na Índia, entre $65 \%$ e $70 \%$ dos(as) trabalhadores(as) pertencem à economia informal, calcula-se que 300 milhões de indianos(as) ficaram sem rendimentos. Na América Latina, cerca de $50 \%$ dos(as) trabalhadores(as) empregam-se no setor informal, ficando, também estes, sem rendimentos.

Por sua vez, a indicação mais eficaz para o combate à pandemia, por parte da Organização Mundial da Saúde (OMS), é o isolamento social, que se torna impraticável para muitos(as) trabalhadores(as) porque os(as) obriga a escolher entre ganhar o pão diário ou ficar em casa e passar fome. Esse é um dos motivos pelos quais o Brasil não consegue, de modo geral, ultrapassar a taxa média de $50 \%$ de isolamento social, pois na falta de um Estado com fortes políticas de proteção do emprego e da renda os(as) trabalhadores(as) não possuem alternativa senão quebrar a recomendação do isolamento social.

O Brasil é caracterizado, historicamente, por profundas desigualdades sociais e econômicas e por uma estruturação precária do mercado de trabalho que aprofunda desigualdades e concentra renda, situação ainda mais agravada com a (contra)reforma trabalhista de 2017 e (contra)reforma da Previdência em 2019.

Como consequência, para Krein, Biavaschi e Teixeira (2020), a atual crise da pandemia de Covid-19 evidencia os problemas advindos de uma sociedade neoliberal, desigual, patriarcal, com aumento expressivo da violência doméstica contra as mulheres, justamente no momento em que, devido ao isolamento social/domiciliar, o trabalho reprodutivo e de cuidados se torna ainda mais imprescindível e se converte no centro das rotinas diárias. Deste modo, o papel do Estado, enquanto indutor do desenvolvimento econômico e propositor de políticas públicas, parece se fazer urgente ao enfrentamento da pandemia. Cabe, portanto, ao Estado intervir no financiamento e na coordenação dos esforços para manter e expandir os serviços básicos essenciais e implementar as indispensáveis medidas 
emergenciais via ampliação do gasto público, sem se preocupar com as restrições fiscais e o endividamento público, como estão fazendo inúmeros países.

Deste modo, em quase todos os países do mundo está havendo uma intervenção maior por parte dos governos para se garantir o isolamento social, tal intervenção se dá por meio da garantia de proteção do emprego e da renda à população. Vários estados nacionais, sobretudo europeus, estão garantindo entre 70 e $80 \%$ dos rendimentos dos(as) trabalhadores(as) para que eles(as) possam ficar em casa e, ainda, auxílio emergencial para os(as) demais, sejam eles(as) informais ou desempregados(as), assegurando, também, recursos para o setor empresarial.

No Brasil, as coisas se passam diferentemente e, portanto, não se consegue ultrapassar um índice de isolamento social que gira em torno de $50 \%$ e, por falta de política pública e de um comitê de gerenciamento da crise sanitária envolvendo a união, estados e municípios, há uma forte pressão por parte do capital pela reabertura e fim do isolamento. Tal reabertura, realizada em momento de curva ascendente da doença fez com que houvesse um aumento no número de contágio e de mortes, obrigando algumas cidades a reverem suas aberturas e estabelecerem, novamente, medidas de quarentena e isolamento. No entanto, tais medidas não serão viáveis sem que os agentes públicos assumam a coordenação do processo.

Os dados referentes ao mundo do trabalho no Brasil pré-pandemia já eram caracterizados, em 2019, por muitos problemas. A partir dos dados da PNADC-2019 (Pesquisa Nacional por Amostra de Domicílio Continuada) sistematizados por Krein, Biavaschi e Teixeira (2020), o mercado de trabalho brasileiro se caracterizava por possuir uma taxa de desemprego aberto na ordem de $11 \%$, mais $5 \%$ de desemprego oculto, totalizando um população desempregada na ordem de $16 \%$. Além disso, o mercado de trabalho brasileiro se caracteriza por baixos salários, ou seja, $30 \%$ da população empregada recebia até um salário mínimo. A elevada taxa de informalidade no mercado de trabalho, cerca de $50 \%$, faz com que esses(as) trabalhadores(as) não tenham acesso aos já escassos direitos trabalhistas.

Assim, diante de um mercado de trabalho como o descrito acima, a pandemia, chega de forma avassaladora. A (in)ação do Estado fez com que 8,1 milhões de trabalhadores(as) formais tivessem a jornada de trabalho e o salário reduzidos sob a égide da Medida Provisória (MP) 936/2020, em que o Estado, ao invés de tutelar os(as) trabalhadores(as), no que diz respeito ao emprego e a renda, facilitou os processos de rescisão contratual e/ ou suspensão de contrato sem rendimentos. A MP estabeleceu, com inúmeros problemas, uma renda emergencial que duraria três meses e, diante da necessidade de ser ampliada, recebe a sinalização, por parte do Palácio do Planalto, de que se aprovada pelo Congresso Nacional haverá possibilidade de veto, pois os custos da manutenção do auxílio, nos termos atuais, ou seja, 600 reais, seriam demasiadamente altos para a União. Diante da MP 936/2020, mais da metade dos acordos trabalhistas foram de suspensão completa dos contratos de trabalho, significando deixar esses(as) trabalhadores(as) sem renda. Além disso, resultados de pesquisa da Fundação Getúlio Vargas (FGV/Ibre) apontam para uma taxa de desemprego aberto em junho de 2020 em torno de $18,7 \%$.

Embora a informalidade seja um fenômeno antigo do mercado de trabalho brasileiro há, hoje, um fenômeno novo, o chamando trabalho "uberizado" ou "plataformizado", ou seja, o trabalho exercido por meio de plataformas digitais. Esse fenômeno traz grandes desafios à realidade do trabalho cujas implicações se agravam nesta conjuntura. No contex to da pandemia, a situação de precariedade, em especial dos(as) trabalhadores(as) 
por aplicativos, se agrava enormemente, uma vez que não possuem nenhum direito trabalhista, pois são reconhecidos como parceiros das redes de aplicativos e não como empregados.

Com o isolamento social realizado por parte da população há uma ampliação da demanda de serviços de entrega em domicílio. Dados recentes da Rede de Estudos e Monitoramento da Reforma Trabalhista (Remir Trabalho), da Unicamp, demonstram que, embora tenha havido um aumento na demanda por esses trabalhadores(as), eles(as) viram seus rendimentos caírem e suas jornadas de trabalho se elevarem na pandemia. Colocando também essa categoria de trabalhadores(as) na linha de frente da possibilidade de contágio, com a agravante de não possuírem nenhum direito trabalhista.

Faz-se evidente, diante desses dados, que uma taxa de isolamento social desejada ou necessária para o achatamento da curva de contágio pelo novo coronavírus, que gira em torno dos $70 \%$, é praticamente inviável no país, caso as medidas estatais não ultrapassem o que realizado até o momento.

Deste modo, a já precária estruturação do mercado de trabalho brasileiro e os ataques que a legislação trabalhista vem sofrendo nos últimos anos compõem o cenário no qual se insere a pandemia, desafiando a capacidade do Estado de fazer frente a este crítico momento da história. É nesse sentido que, segundo Krein, Biavaschi e Teixeira (2020), a pauta do combate às desigualdades precisaria ocupar o centro da agenda estatal, e o papel ativo do Estado deveria voltar-se para três eixos fundamentais, como estão fazendo a maior parte dos países atingidos pela pandemia, ou seja, a garantia do emprego e condições de trabalho, a proteção da renda e outras garantias necessárias ao direito à vida.

Já para aqueles(as) que estão desenvolvendo trabalho remoto, cabe destacar a intensidade do trabalho e o forte controle das atividades permitidas pelos vários sistemas digitais de vigilância e controle. As mulheres, por sua vez, estão vivendo com maior intensidade a já conhecida dupla/tripla jornada de trabalho. No caso das mulheres cientistas, por exemplo, editores de revistas divulgam que o número de artigos submetidos por mulheres caiu drasticamente em relação ao período anterior à pandemia, enquanto o número de artigos submetidos por homens aumentou (Flaherty, 2020).

Ao analisar o mundo do trabalho, a partir desta pandemia, Antunes (2020) aponta algumas possibilidades que poderão se confirmar no futuro próximo. O trabalho on-line, digital, home-office, teletrabalho (ainda que haja diferenças legais entre eles) indicam que poderá haver, para uma categoria considerável de trabalhadores, uma intensificação de atividades com muitas vantagens para o capital e outras poucas para os(as) trabalhadores(as). Processos como individualização do trabalho, distanciamento social, menos relações solidárias e coletivas no espaço de trabalho, distanciamento da organização sindical, tendência a eliminação de direitos, fim da separação entre tempo de trabalho e tempo de vida, duplicação e justaposição entre trabalho produtivo e trabalho reprodutivo, com intensificação do trabalho feminino, podem aumentar ainda mais a desigual divisão sociossexual e racial do trabalho. Forte impacto sofrerá a educação por meio do chamando ensino à distância. Ainda que possa haver maiores dificuldades para a adoção de tal sistema, ou sistemas híbridos, em escolas de nível médio, sejam elas públicas ou privadas, certamente haverá grande avanço no ensino superior, sobretudo no ensino superior privado, embora, no atual governo, haja a intencionalidade de expandir o ensino à distância para as universidades públicas, impactando o trabalho docente e impossibilitando a vivência acadêmica e universitária dos alunos. 
Assim, com a pandemia, têm-se uma exacerbação das consequências do neoliberalismo que, embora centrado ideologicamente na categoria do mercado, constitui-se para além de uma política econômica ou uma ideologia, produzindo regras e disciplinas que ultrapassam o mercado, ao mesmo tempo que produz o desmantelamento de muitas normas, regras e leis em relação ao trabalho, instaurando aquilo que Dardot e Laval (2016) denominam de 'a nova razão de mundo'. Com o neoliberalismo, a precariedade do trabalho se transforma em precariedade da vida, na qual a lógica do capital inundou todas as relações sociais e a todas as esferas da vida.

Esse processo, como ressalta, Ballestrin (2018), produz os sujeitos políticos tocados não somente pelo desinteresse, desconfiança e apatia políticas, como também pelo individualismo, consumismo e depressão. A desesperança política, a preguiça intelectual, o elogio à ignorância e a ode ao anti-intelectualismo teriam se tornado elementos fundamentais para o crescimento da intolerância e da violência.

No entanto, a reconfiguração do jogo democrático, pós-crise de 2008, evidencia a possibilidade de se caminhar para um aprofundamento desse processo de desdemocratização - com a ascensão de uma nova direita populista e extremista em muitos lugares - ou para uma democratização da democracia - por meio de muitos movimentos sociais que tomaram as ruas na última década em vários países. O caminho que ainda encontra-se aberto está, segundo Brown (2019), se fechando.

Ainda que as experiências dos movimentos sociais das últimas décadas pareçam pequenas diante dos desafios que se apresentam, ainda mais diante de uma pandemia, é necessário sublinhar que o sistema neoliberal é, hoje, muito mais rígido, mais austero porque é também muito mais frágil. Ele está se tornando mais violento no seu modo de impor-se, porque necessita da violência para enfrentar sua fragilidade, enfrentar a defesa de um sistema que está gerando cada vez mais exclusão, aumento da pobreza, das desigualdades no mundo todo e destruindo o planeta.

Faz-se necessário, neste momento, que a imaginação política esteja baseada em novas experiências utópicas. Para tanto, é urgente partir das experiências existentes, das experiências feitas cotidianamente por tantas mulheres e homens trabalhadoras/es que buscam fazer-se a partir de uma racionalidade que não é produzida e controlada pelo neoliberalismo. Estas experiências, como mencionado, existem em todas as partes do mundo e buscam recompor os relações sociais e de trabalho, o tecido social por meio de novos fundamentos que consentem prefigurar uma sociedade futura ou um futuro para a sociedade.

Há que se ter uma nova articulação entre o projeto de emancipação humana e as experiências atuais, evidenciando a importância dos movimentos sociais e instituições que associam formas efetivas entre a democracia direta e a democracia representativa, passando pela discussão sobre o predomínio da propriedade privada, sobretudo em relação aos bens comuns e a privatização de todos os aspectos da vida. Este é o desafio lançado em face às (im)previsíveis novas pandemias que poderão surgir mundo, como já alertaram as/ os cientistas. 


\section{Considerações finais}

O presente artigo pretendeu ser uma contribuição para os estudos no campo da Psicologia Social do Trabalho, partindo de pesquisas advindas do campo da sociologia econômica e do trabalho, buscando dialogar, de forma interdisciplinar, com uma perspectiva contemporânea sobre o mundo do trabalho.

Deste modo, foram destacadas algumas implicações e possíveis consequências da Covid-19 para o mundo do trabalho diante de relações trabalhistas já precárias e precarizadas pelas políticas neoliberais, que produzem não apenas efeitos econômicos e políticos, mas também outras e novas subjetividades em um contexto de questionamento e/ou erosão das democracias liberais.

A contribuição do texto, portanto está na busca por relacionar as análises econômicas e políticas sobre o neoliberalismo com os estudos mais recentes sobre a erosão das democracias, a ascensão da extrema-direita e de governos autoritários no mundo, incluindo o Brasil, com ênfase na constituição das subjetividades diante do chamado neoconservadorismo, e, a partir desta relação, o enquadramento da pandemia de Covid-19 e suas consequências para o mundo do trabalho.

As reflexões aqui propostas trazem as limitações de um trabalho escrito em meio ao processo da pandemia em curso. Deste modo, essas reflexões constituem-se em apontamentos que, embora calcados no exame da realidade concreta, podem, no futuro, apresentar outros desdobramentos.

No entanto, as reflexões aqui expostas podem expressar a ideia segundo a qual a crise estabelecida em meio ao processo de (de)desmocratização ou pós-democracia poderia, também, abrir as portas para um processo de democratização da democracia, pois, com o fim da pandemia, podem ganhar impulso tanto tendências autoritárias e nacionalistas como saídas mais democratizantes.

Eventos de proporções e consequências mundiais, como o alastrar-se da Covid-19, podem impulsionar discussões em torno da radicalização da democracia e dos bens públicos, como a importância e valorização de sistemas púbicos de saúde; redes de proteção; a educação compreendida como um direito e um bem público; segurança, lazer, cultura, água, saneamento básico, o bem viver, enfim, políticas que se pautem pelo comum. No entanto, a fragilidade em torno de fortes movimentos sociais capazes de impulsionar tal perspectiva ainda persiste e pode limitar esse processo.

Davis e Klein (2020) radicadas no conceito de crise, que por definição abre, principia, escancara o sentido das múltiplas possibilidades que se colocam historicamente, afirmam que teria chegado o momento de serem postos na mesa todas as exigências, pois essa pandemia e a necessidade do isolamento social, do fechamento das atividades econômicas teria deixado ainda mais claro e evidente que "somos nós, trabalhadores(as) que mantemos o mundo em pé!", ou seja, a pandemia do novo coronavírus demonstraria de forma cabal, contrariamente às teses do fim da sociedade do trabalho, que o trabalho é estruturante da vida social e, portanto poderia, ainda, ser forte elemento mobilizador de mudanças. 


\section{Referências}

Alves, G. (2011). Trabalho e Subjetividade: o espírito do toyotismo na era do capitalismo manipulatório. São Paulo: Boitempo.

Anderson, P. (1995). Balanço do Neoliberalismo. In E. Sader \& P. Gentili (Orgs.), Pós-Neoliberalismo: as políticas sociais e o Estado Democrático (pp. 9-23). Rio de Janeiro: Paz e Terra.

Antunes, R. (2000). Os sentidos do trabalho. São Paulo: Boitempo.

Antunes, R. (2020). Coronavírus: o trabalho sob fogo cruzado. São Paulo: Boitempo.

Ballestrin, L. (2018). O debate pós-democrático no século XXI. Revista Sul-Americana de Ciência Política, 4(2), 149-164.

Batista, A., Antunes, B., Faveret, G., Peres, I., Marchesi, J., Cunha, J., Dantas, L. et al. (2020). Análise socioeconômica da taxa de letalidade da Covid-19 no Brasil- nota técnica 11. Núcleo de Operações e Inteligência em Saúde, 11. https://sites.google.com/view/nois-pucrio/ publicações? authuser $=0$.

Braga, R. (2017). A Rebeldia do Precariado: trabalho e neoliberalismo no sul global. São Paulo: Boitempo.

Berger, IK. (2020, March, 12). The man Who saw the Pandemic coming Will the world now wake up to the global threat of zoonotic diseases? Nautilus. Recuperado de http://nautil.us/ issue/83/intelligence/the-man-who-saw-the-pandemic-coming

Brown, W. (2019). Nas ruínas do neoliberalismo: a ascensão da política antidemocrática no ocidente. São Paulo: Filosófica Politeia.

Chesnais, F. (2005). A finança mundializada. São Paulo: Boitempo.

Dardot, P. \& Laval, C. (2016). A Nova Razão do Mundo: ensaio sobre a sociedade neoliberal. São Paulo: Boitempo.

Davis, Â. \& Klein, N. (2020). Construindo Movimentos: uma conversa em tempos de pandemia. São Paulo: Boitempo.

Dweck, E. (2020, março 15). Austeridade é a maior aliada do coronavírus no Brasil. Jacobin. Recuperado de https://jacobin.com.br/2020/03/austeridade-e-a-maior-aliada-do-coronavirus-no-brasil/

Flaherty, C. (2020). No room of one's own. Inside Higher. Recuperado de https://www.insidehighered.com/news/2020/04/21/early-journal-submission-data-suggest-covid-19-tanking-womens-research-productivity

Harvey, D. (2020, março 22). Políticas anticapitalistas em tempos de Covid-19. Idéias de Esquerda. Recuperado de http://www.esquerdadiario.com.br/Politicas-anticapitalistas-em-tempos-de-COVID-19

Krein, J. D., Biavaschi, M., \& Teixeira, M. (2020, maio 19). Emprego, trabalho e renda para garantir o direito à vida. Friedrich-Ebert-Stiftung Brasil. Recuperado de https://www.fes-brasil. org/detalhe/emprego-trabalho-e-renda-para-garantir-o-direito-a-vida/

Leite, K. C. (2020). Trabalho precário: precariado, vidas precárias e processos de resistências. Revista de Ciências Sociais - Política E Trabalho 51, 108-125.

Leite, K. C. (2007). Economia de Comunhão: a construção da reciprocidade nas relações entre capital, sociedade e estado. São Paulo: Annablume/FAPESP. 
Mazeiro, G. (2020). Guedes: vamos usar recurso público com grandes empresas e ganhar dinheiro. UOL. Recuperado de https://noticias.uol.com.br/politica/ultimas-noticias/2020/05/22/guedes-vamos-usar-recurso-publico-com-grandes-empresas-e-ganhar-dinheiro.htm

Medida Provisória n. 936, 20 de março de 2020 (2020). Institui o Programa Emergencial de Manutenção do Emprego e da Renda e dispõe sobre medidas trabalhistas complementares. DF: Presidência da República. Recuperado de https://www.congressonacional.leg.br/materias/medidas-provisorias/-/mpv/141375

Ministério da Saúde. (2020). Coronavírus Brasil. Recuperado de https://covid.saude.gov.br

Mounk, Y. (2018). O povo contra a democracia: por que nossa liberdade corre perigo e como salvá-la. São Paulo: Companhia das Letras.

Organização Internacional do Trabalho [OIT]. (2015). Labour market reforms since the crisis: Drivers and consequences. Genova: Adascalitei, Dragos \& Morano, Clemente.

Santos, B. (2020). A Cruel Pedagogia do Vírus. São Paulo. Boitempo.

SEBRAE. (2020). Pequenos negócios em número. Institucional. Recuperado de https://m.sebrae. com.br/sites/PortalSebrae/ufs/sp/sebraeaz/pequenos-negocios-em-numeros, 12e879436344 7510VgnVCM1000004c00210aRCRD

REMIR/UNICAMP. (2020). Queda na renda de 68\% dos entregadores por aplicativo motiva greve da categoria. Recuperado de https://www.eco.unicamp.br/remir/index.php/sindicalismo/181-queda-na-renda-de-68-dos-entregadores-por-aplicativo-motiva-greve-da-categoria

Rossi, P. (2020). Lições do coronavírus para a sociedade do futuro. Friedrich-Ebert-Stiftung Brasil. Recuperado de https://www.fes-brasil.org/detalhe/licoes-do-coronavirus-para-a-sociedade-do-futuro/

Tesini, B. (2020, abril). Síndrome respiratória aguda grave (Covid-19, MERS e SARS). Manual MSD. Recuperado de https://www.msdmanuals.com/pt/profissional/doenças-infecciosas/v\%C3\%ADrus-respiratórios/coronav\%C3\%ADrus-e-s\%C3\%ADndromes-respiratórias-agudas-covid-19,-mers-e-sars

Wiston-Salem, A. C. (2020). Coronavírus: por que a população negra é desproporcionalmente afetada nos EUA?. BBC Neres Brasil. Recuperado de https://www.bbc.com/portuguese/internacional-52267566 


\section{KELEN CHRISTINA LEITE}

https://orcid.org/0000-0002-8590-1857

Doutora em Ciências Sociais pela Universidade Federal de São Carlos (2005) com estágio doutoral em Economia Civile pela Università Degli Studi di MilanoBicocca (Itália 2003-2004). Professora Associada da Universidade Federal de São Carlos, junto ao Departamento de Ciências Humanas e Educação DCHE. Visiting Professor na Università Sapienza de Roma (Itália 2018-2019). Credenciada junto ao Programa de Pós-Graduação em Estudos da Condição Humana (PPGECH/UFSCar).

Endereço: Universidade Federal de São Carlos (DCHE), Rodovia João Leme dos Santos, (SP-264), Km 110, s/n - Itinga, Sorocaba/SP, CEP 18052-780.

Email: kelen@ufscar.br

\begin{tabular}{|l|l|}
\hline Histórico & $\begin{array}{l}\text { Sulbmissão: 28/06/2020 } \\
\text { Revisão: 23/07/2020 } \\
\text { Aceite: 24/07/2020 }\end{array}$ \\
\hline $\begin{array}{l}\text { Contribuição } \\
\text { dos autores }\end{array}$ & Não se aplica. \\
\hline $\begin{array}{l}\text { Consentimento } \\
\text { de uso de imagem }\end{array}$ & Não se aplica. \\
\hline $\begin{array}{l}\text { Aprovação, ética } \\
\text { e consentimento }\end{array}$ & Não se aplica. \\
\hline Financiamento & Não houve financiamento. \\
\hline
\end{tabular}

